\title{
Design and Development of Cloud Learning Tool for English Sentence Patterns
}

\author{
Ching-Fan Chen ${ }^{1}$ \\ ${ }^{1}$ Department of Educational Technology, Tamkang University, Taiwan \\ Correspondence: Ching-Fan Chen, Department of Educational Technology, Tamkang University, 151 Yingzhuan \\ Road, Danshui Dist., New Taipei City, Taiwan. E-mail: cfchen@mail.tku.edu.tw
}

Received: July 8, 2019 Accepted: August 18, 2019 Online Published: October 13, 2019

doi:10.5539/ijel.v9n6p93 URL: https://doi.org/10.5539/ijel.v9n6p93

\begin{abstract}
This study aims at providing Taiwanese students at different levels of study with a cloud language learning tool. The design of the learning tool can be divided into three stages. The first stage is the design of the curriculum. It combines paper learning log sheet with a simple computer program to help students write short essays and "tell" the stories. Findings of this study showed that students were highly motivated to make use of the computer learning tool to practice English sentence patterns and to create short essays. In the second stage, the researcher developed a cloud English learning tool that can be used in different types of computer facilities. This learning tool aims at helping students practicing English sentence patterns and at providing teachers with tools to monitor students learning process and performance. In the third stage, the researcher applied this computer learning tool to vocational high school students. The participants were two classes of high school seniors in New Taipei city, with 34 students in each class. One of the two classes was assigned as the experimental group and the other class the control group. The experimental group practiced English sentence patterns, using the cloud English learning tool. The control group was provided with paper handouts and was taught in a traditional way. The results showed a significant difference in performance between the two groups of students, with an $\mathrm{F}$ value 4.563 $(p<.05)$. The experimental group had higher mean scores than the control group had. We may conclude that the cloud English learning tool can improve vocational high school students' English writing skills.

In the three-stage study, the researcher found that students at different levels of study used different types of computer facilities, for example, senior high school students used smart phones or notebooks, junior high school students used desktops in the computer lab, and elementary school students used learning log sheets to learn. Therefore, the researcher integrated HTML 5 and jQuery into a learning system and provided teachers with learning logs forms to download. That is, teachers can apply this learning system to students of different levels of study. The goal of this learning tool is to help students write short English essays.
\end{abstract}

Keywords: cloud learning, English teaching, digital storytelling, information technology integration into instruction, Mandala Thinking Method, English writing abilities

\section{Introduction}

After considerable analyses of high school EFL students' writing in English, English teachers realized that high school students' problems in writing lie in the fact that students do not have a clear idea of how to put English vocabulary words in the right order in a sentence. It is not uncommon that they put vocabulary words in a random order to form a sentence, which is usually considered ungrammatical. Saddler, Behforooz, and Asaro (2008) pointed out that the problems with writing may be caused by students' insufficient knowledge of English sentence patterns, and it is quite often that EFL students make grammatical errors and have problems producing compound or complex sentences. In order to promote EFL students' writing ability, nurture their global perspective, and motivate them to learn English, the researcher propose to make use of different learning programs online to create a framework of basic English sentence patterns, to which students can apply to create their own short stories.

This study aims at providing different levels of EFL students in Taiwan with a cloud English learning tool. The process of the entire project was divided into three stages. The first stage was curriculum design. The researcher made use of existing learning log sheets and simple computer programs to design the curriculum, focusing on junior high school students. Results of the experimental study showed that students could easily create a short 
story and "tell" the story through the help of the pictures and designed learning log form. The researcher found that students were motivated to learn English and had better ideas of English sentence patterns. The teacher also used the approach to encourage students to practice and produce sentences. However, teachers may be discouraged by the limited time they can use in the classroom to have students practice sentence patterns. This drawback has led the researcher to develop an online English learning program in the second stage. It was hoped that English teachers may use the cloud English program to monitor students' learning and to help them with their ability to write appropriate sentences. English teachers' assessment of the learning tool and their suggestions for further improvement were sincerely welcome. In the third stage, we designed a specific curriculum and applied the online English learning program to vocational high school students and found that students' English proficiency has improved significantly.

Our three-stage experimental study was conducted for students at different levels of study, and different levels of students have different learning tools and learning environments. At senior high school level, students may carry their mobile phones or laptops to the school; while, at the junior high school level, students have to go to a computer lab to get access to the Internet. As for elementary school level, students mainly use learning log sheet to record what they have learned. To solve the problems of diverse learning tools, the researcher integrated HTML and jQuery with digital database in a language learning system. This system may allow web pages to appear in different digital tools, and learning log sheets are also available for teachers to download. Most of all, this program can be used for different levels of students.

\section{Method}

\subsection{Applying Mandala Thought Pattern to English Writing}

Mandala is initially a religious totem, and it was later transformed to represent strategies of thinking and planning in the form of a $3 \times 3$ magic square. It helps individuals in their process of thinking. According to Imaizumi (1989), the divergent and the clock-wise patterns in Mandala can especially help students in the process of their creative thinking. Although Mandala can be as simple as a $3 \times 3$ magic square, its divergent, convergent, systematical, integral, and balanced nature of thinking may lead to creation of new meaningful construct as shown in Figure 1 and Figure 2.

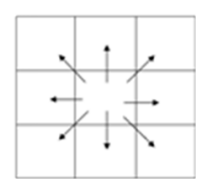

Figure 1. Mandala Divergent Ways of Thinking

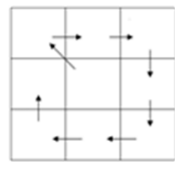

Figure 2. Mandala Clock-wise Ways of thinking

Various factors may affect the quality of writing pieces. However, good writing pieces rely heavily on strategies writers use in their writing process. Writers may face inter-related issues in their writing process, and one change in a step may influence the rest of a writing piece. Writing strategies are generally developed to solve the problems that occur in the writing process. Among the issues in the writing process, planning and revising may be the most salient ones.

\section{- Strategies in Planning as Related to Divergent Mandala}

In his study, Kellogg (1988) found that those who used advanced writing strategies produced superior writing pieces. He concluded that careful outline planning helps writers focusing on transforming their thoughts into words and hence improve the quality of writing. Advance-planning can definitely facilitate the flow of the entire writing.

Ways of thinking in Mandala thought patterns may be applied to the writing process. Among them, visual thinking and systematic thinking are regarded as of great help in visualizing the writer's thoughts and systematically connecting different thoughts (Chen, 2006).

\section{- Strategies in Revising as related to Clock-wise Mandala}

Studies has shown that good writers always spend more time revising their writing (Bereiter \& Scardamalia, 1987). In the process of revising and editing, writers may probe different errors or problems in writing at the same time. For example, they may find inappropriate use concerning phonetics, syntax, and semantics while doing spelling check (Levy, Newwell, Snyder, \& Carey, 1986). 
In the course of revising, the convergent and balanced ways of thinking in Mandala thought patterns may help extract important components and carefully select relevant concepts. Those irrelevant and unimportant concepts are then excluded in the process. Based on the idea of Mandala thought patterns, the researcher designed a Clock-wise Mandala learning sheet as shown in Figure 3. Students fill in the blank circles with the vocabulary words they have learned. They then use sentence patterns and story pictures to create short essays.

Based on the idea of Mandala thought patterns, the researcher designed a curriculum along with a learning log sheet for junior high school students, in the hope that they would be able to produce short stories through practices of sentence patterns, and make simple animated movies using Photo Story computer software, and upload their products uploaded to YouTube to share with their classmates in the classroom.

\subsection{Design of the Mandala English Sentence Pattern Curriculum}

The present study aims at investigating how integrating Mandala thought patterns into digital English story-telling class may affect junior high school students' writing in English and at developing a model of English story telling in the classroom based on theories of story-telling, second language writing, and Mandala thought patterns.

- Mandala English sentence pattern instruction

First, students will be asked apply Mandala thought patterns to analyze the main elements of a sentence and fill in each of the petals in the Mandala totem with different syntactic elements and to integrate all the elements to form a sentence. At the initial stage of practice, writing logical sentences was not strictly required. Students were asked to produce as many sentences as they could. They were then asked to revise the sentences they had produced and integrate the sentences into a short essay and share it and comment on each other's essay with their classmates. The entire procedure is shown in Figure 3.

\section{- Story Map and Mandala 5W analysis}

(1) Story map: Students need to have basic framework of sentence patterns and storyline in order for them to use PowerPoint and Photo Story3 computer software to create their own animate movies. Mandala thought pattern allows students to formulate their story first, then they present their story in the form of a story map based on the ideas they formed earlier as shown in Figure 4.

(2) Mandala 5W analysis and story map: The idea of story map is intended to help students develop the framework of a story. In the course of curriculum design, Mandala $5 \mathrm{~W}$ analysis can be considered as the bridge connecting story map and the final version of the storyboard as shown in Figure 5.

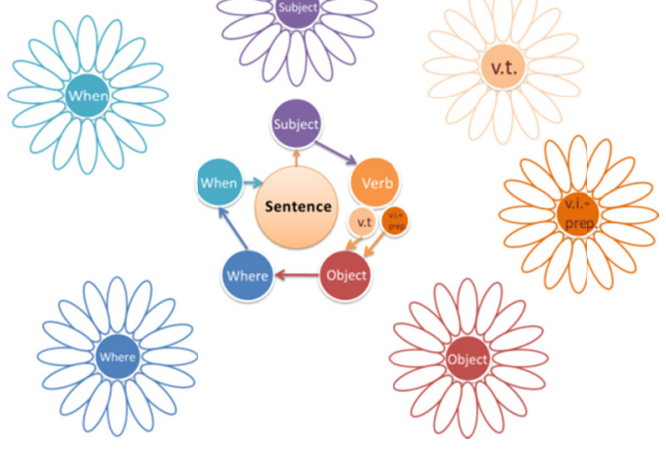

Figure 3. Mandala sentence patterns

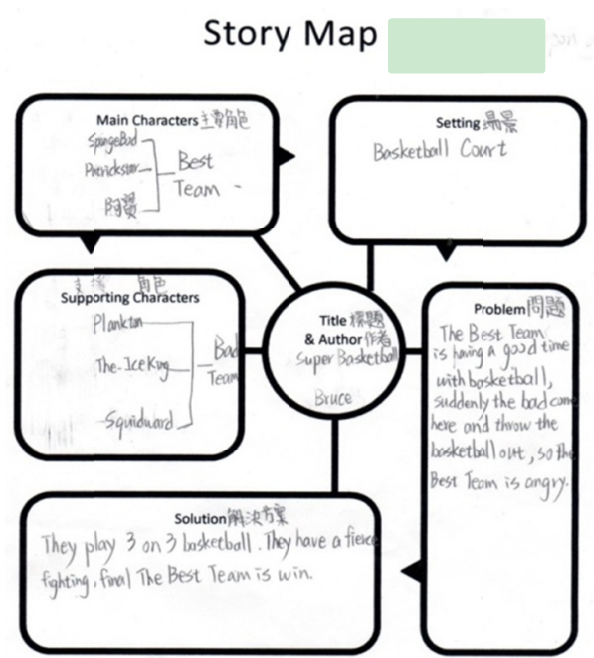

Figure 4. Story map 


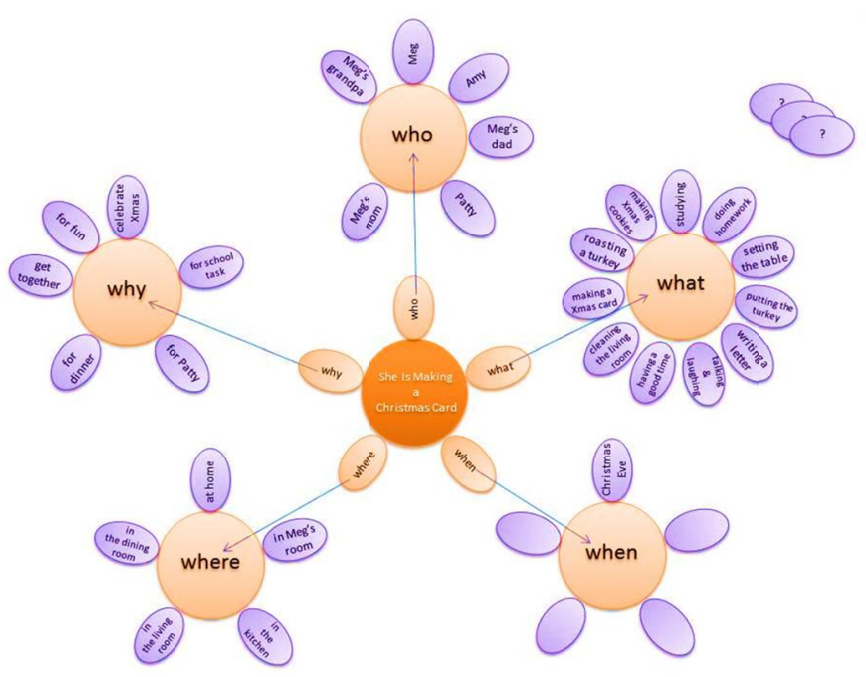

Figure 5. Mandala 5W analysis

\section{Who-Main Character, Supporting Character}

Students were required to relate the main characters and supporting characters and the relationship between or among them. They were also required to decide on the significance of each character and the role each character plays in the story.

II. Why-Problem

This part in the Mandala 5W analysis required students to describe and analyze the cause of a problem in the story and enabled students to develop deeper thinking to produce more detailed analysis.

III. Where, When-Setting

Spatial and temporal elements in a story may affect the development of the entire story. Students had to decide on a time period a place so that the entire story can be logical and reasonable.

IV. What-Solution

Having identified the problems in the story that to be solved, students might think about the ways to solve the problems. It might require them to list each step or action needed to solve the problems.

- Storyboard and story scripts in Mandala totem

In the course of writing story scripts on the story board, students were asked to fill in the Mandala totems with their ideas derived for Mandala 5W analysis. The convergent and sequential features of Mandala thought patterns allowed students to decide on the significance, sequence, and logics of the story and eliminate those redundant, unnecessary, and illogical details. The essential components would be kept as the basis of the story script.

\section{- Digital story-telling-Recording and Presentation}

To present digital stories, an easy and user-friendly movie-editing computer software was chosen for students to use to eliminate possible learning barriers caused by computer skills.

The last step, including recording, import and export of sounds and images, was done, using Microsoft freeware Photo Story. The movies were saved as .wmv files and were uploaded to YouTube website to share with others as shown in Figure 8. 

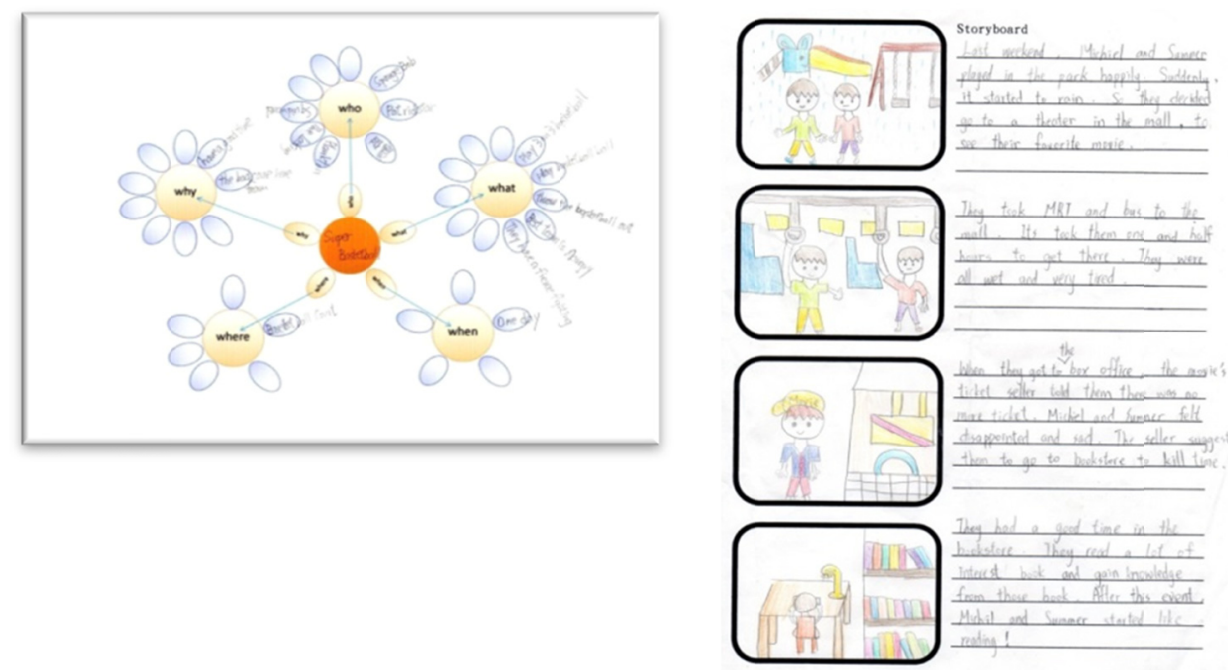

Figure 6. Story scripts mandala

Figure 7. Storyboard

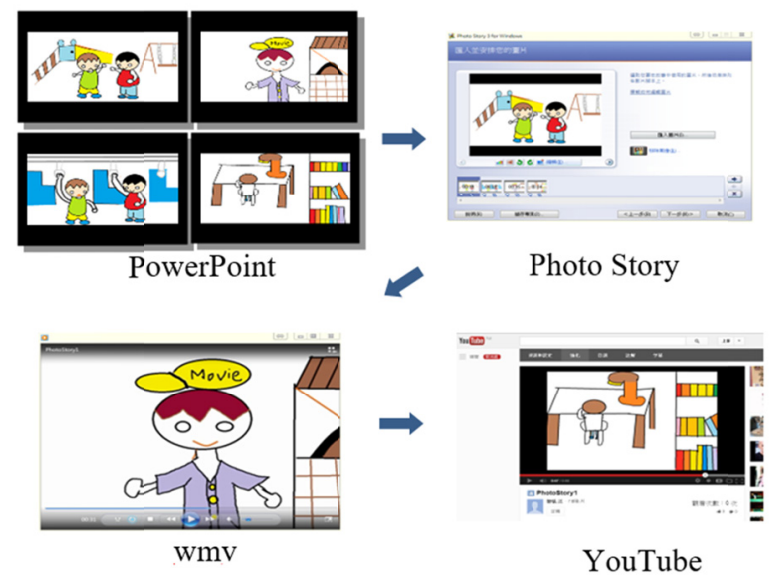

Figure 8. Flowchart of storytelling

Based on the curriculum design described above, the researcher conducted a quasi-experimental study. Participants were 58 junior high school students in New Taipei City in Taiwan. They were recruited through convenience sampling procedures. Participants were in two classes. One class was randomly assigned as the experimental group, and the other the control group. The entire research study lasted eight weeks. The experimental group was trained the Mandala thought patterns, and the control group was instructed in an integrated e-learning environment. Before the instruction, the two groups of students took a pre-test to examine their English writing skills. At the end of the instruction, the two groups of students took a post-test. The test results were analyzed, using ANCOVA statistical program, to examine the differences, if any, between the control group and the experimental group. The statistical results show that

- Indirect English writing tests:

Both low-achieving and high-achieving students in the experimental group performed much better in indirect writing tests, such as vocabulary, grammar, and sentence structure, than those in the control group did. The differences were significant.

- Direct English writing tests:

Both low-achieving and high-achieving students in the experimental group performed much better in direct writing tests, such as sentence combination, picture story-telling, and essay writing, than those in the control group did. The differences again were significant.

- Overall English writing skill tests: 
Both low-achieving and high-achieving students in the experimental group performed superior to those in the control group. The differences were significant.

From findings of the study, we may conclude that integrating Mandala approach with digital story-telling instructional method benefits both low-achieving and high-achieving students in their writing in English. More apparently, in indirect English writing tests, Mandala approach had greater influence on low-achieving students than on high-achieving students. It may be because high-achieving students may already possess basic knowledge of vocabulary and grammar, which were tested in the indirect writing tests. Therefore, they performed better than low-achieving students. Furthermore, the curriculum design provided students with different lesson units. Students have opportunities to repeatedly learn vocabulary words and sentence patterns. In addition to leaving students with deeper impression of vocabulary words and sentence patterns, Mandala approach may facilitate students' reading comprehension and enhance students' awareness of the relationships between words, phrases, and sentences. They will not limit their interpretation of words and phrases to their literal meanings, but to wider interpretations of their use in different contexts.

\section{Development of Cloud Learning Tool for English Sentence Patterns}

From the first stage of experiment, the Mandala approach was found to be an efficient English learning tool. In order to provide students with an autonomous learning environment after class and to help teachers monitor students' learning, the researcher further developed cloud learning tool for English sentence patterns. The entire function of the tool is illustrated as follows.

\subsection{Instruction to Teachers:}

There are two main tasks for teachers to do before the instruction: formulating sentence patterns to be taught and developing classroom management and activities. Thus, the two tasks appear in the main menu of the initial page as shown in Figure 9.

Teachers first need to create a database to include sentence patterns to be taught. These sentence patterns can be repeatedly used in different learning activities. As shown in Figure 10 (left), the colored columns signify that they can be switched with one another. To simplify the task, just click and drag the column to be moved to change the order of the column.

As shown in Figure 10 (right), the class management menu allows teachers to monitor individual student's learning and then reflect on their instructional activities. The 'Remarks' column is added to the menu that allows teachers to record different features of different classes.

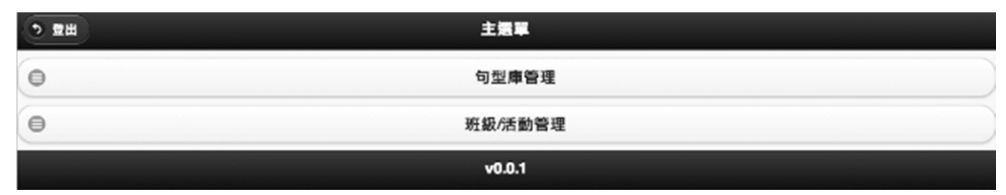

Figure 9. The main menu after the teacher logs in

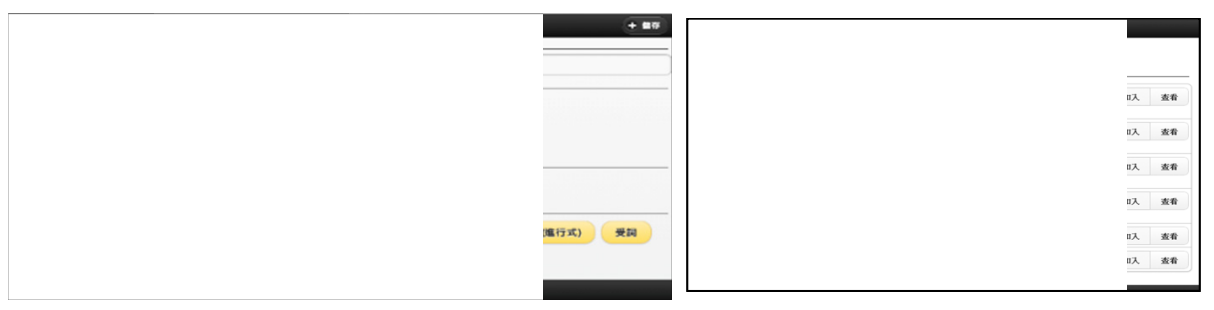

Figure 10. The interface of sentence patterns and class management

Teachers first choose the class or classes to be involved and then develop one or several activities as shown in Figure 11 (left). Then, based on the sentence pattern database, develop activities to allow students to practice. To make the most use of mobile phones and laptops, a QR Code is provided to help students locate the URL of the website as shown in Figure 11 (right). 

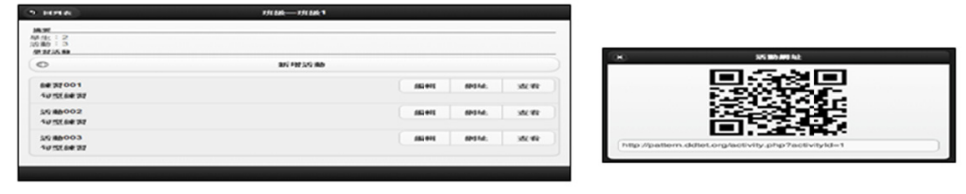

Figure 11. Activity menu and QR code

Teachers may create a list of sentence patterns and present them in columns with examples so that students may have clearer ideas of each sentence pattern as shown in Figure 12-1 and Figure 12-2.

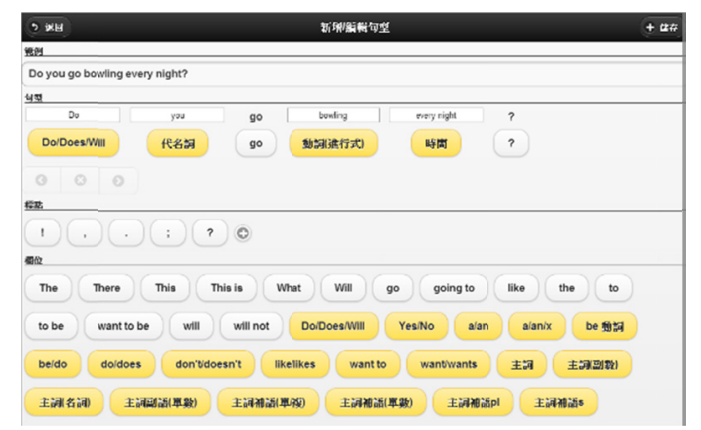

Figure 12-1. Sentence pattern interface created by the teacher

\begin{tabular}{|c|c|}
\hline $0 \times 8$ & \\
\hline \multirow{2}{*}{\multicolumn{2}{|c|}{ a }} \\
\hline & \\
\hline 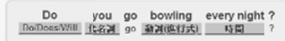 & 0 \\
\hline 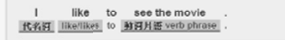 & 0 an \\
\hline 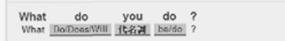 & $0=5$ \\
\hline 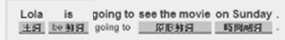 & 0 : \\
\hline 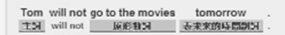 & O \\
\hline
\end{tabular}

Figure 12-2. The interface to cover all the sentence patterns

\subsection{Instruction to Learners}

When learners are invited to create an account to start using the cloud learning tool and to participate in the activities, they will see a web page demonstrating the entire learning procedure. Learners are allowed to fill in the blanks with vocabulary words they have learned to create sentences and, as required, they may revise the sentences as shown in Figure 13 (left) or they may choose the sentence patterns they wish to learn and create new sentences as shown in Figure 13 (right).

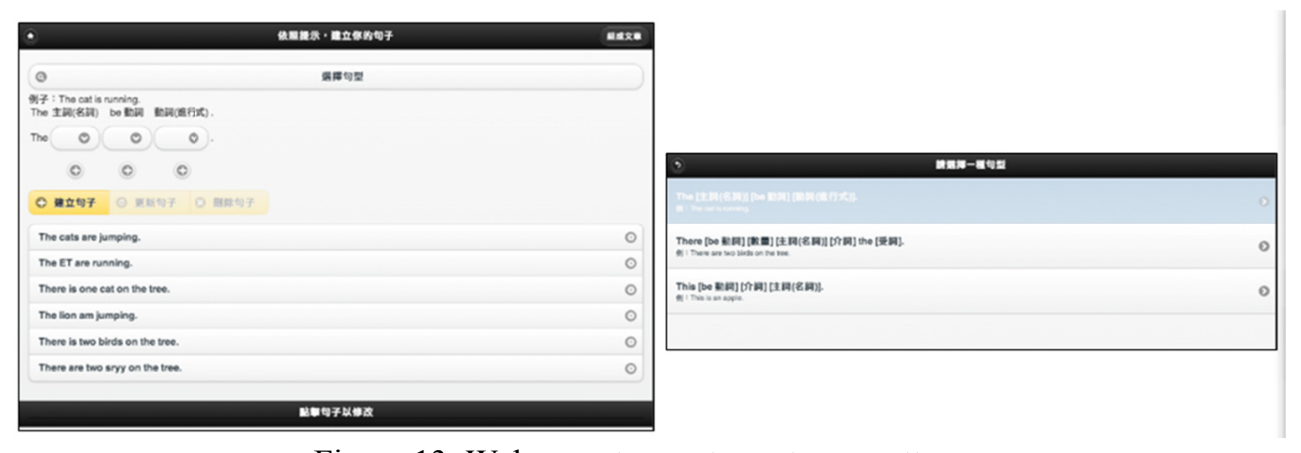

Figure 13. Web page to create sentence patterns 
In the course of learning, one of the objectives is to enable students to repeatedly encounter the words and to use the words correctly. To achieve this goal, learners are required to provide the correct number and tense of the words in the changeable columns before they can organize them into sentences. In order to save learners' time spent keying in vocabulary words, the same vocabulary words can be used in different sentence patterns in the same column so that learners may pay greater attention to sentence patterns.

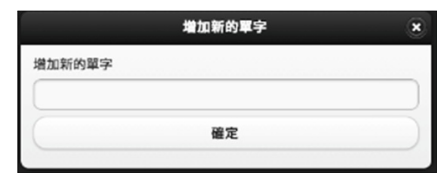

Figure 14. Pop-up dialogue box used to add new words

Having created the sentence pattern database, learners need to choose appropriate sentences to create an essay. The URL interface allows learners to put all the sentences in the same web page. This may reduce the distraction of attention caused by moving back and forth of the web page. Learners are first required to choose the sentences they need, and then they put all the sentences in an appropriate order. Finally, they complete the entire learning process by saving the file and submit it as shown in Figure 15.

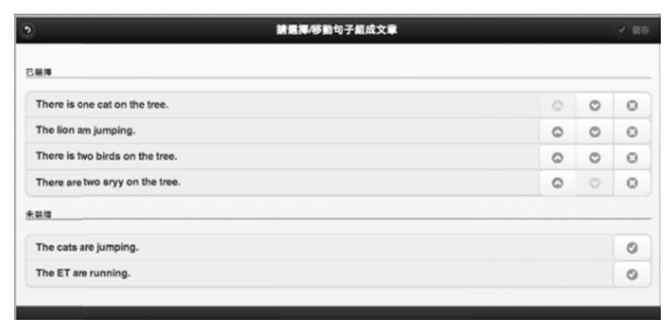

Figure 15. A short essay created by the learner

When learners are practicing through all the procedures, instructors may monitor learners learning process and read the essays uploaded by learners as shown in Figure 16 (left), and they can also classify the sentences created by learners as shown in Figure 16 (right). It is not necessary for instructors to talk to learners face to face in order to figure out their learning situation. Instructors may provide learners with immediate feedback or error correction or they may use computer screen or whiteboard to have more interactions or discussions with learners.

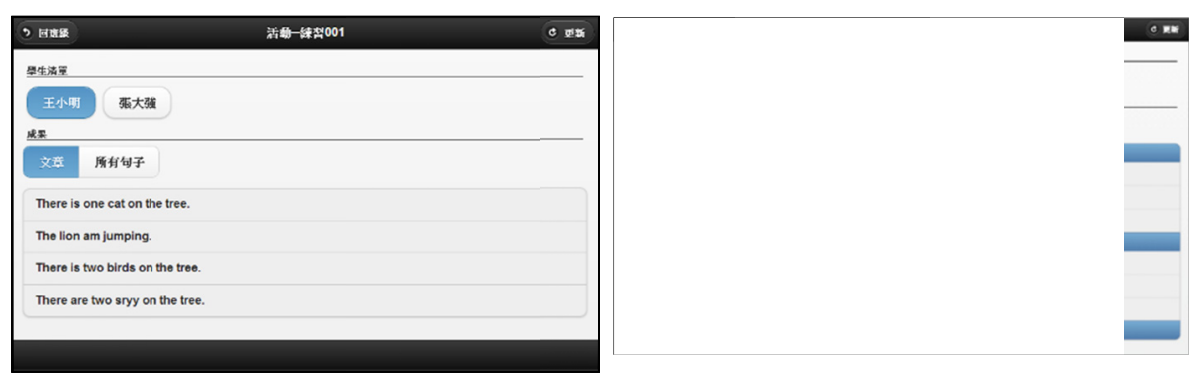

Figure 16. Instructors check learners' learning outcomes

The researcher investigated how the cloud supplementary teaching tool may affect vocational high school students' English sentence writing skills. Participants were vocational high school students in Northern Taiwan. The sentence patterns presented in the English textbook were mainly used as the instructional material. The cloud language learning tool was used in the investigation of sentence pattern instruction. The study was designed under the quasi-experimental research paradigm, using pre- and post-test. Participants were two classes of vocational high school seniors from New Taipei City. One class was assigned as the experimental group; the 
other the control group. Both the two groups of students were given "An overview of English sentence patterns" handouts. The students in the experimental group were instructed with the help of the cloud supplementary teaching tool; while the students in the control group were not. This is to investigate how cloud supplementary teaching tool may help vocational high students with their English writing skills.

\subsection{Cloud English Sentence Pattern Learning Tool as Applied in Classroom Instruction}

This language learning tool can be used to test that test students' writing skills. The entire testing system tests students' basic writing skills, including linguistic knowledge, grammar, and sentence structure. The test questions were developed based on the third volume, unit 1 of Tung-Da vocational high school English textbook. Test questions included four parts: grammar multiple choice, sentence structure, sentence paraphrase, and sentence translation. The teacher designed their own paper-and-pencil test questions to explore students' English writing ability. There are ten multiple choice questions. Each right answer was awarded four points. As for the sentence structure, sentence paraphrase, and sentence translation parts, there are four questions for each part and each question took five points. The full marks that can be gained were 100 points. The rubric used to count students' total points was:

5 points $\rightarrow$ correct

4 points $\rightarrow$ acceptable sentence structure with one minor error

3 points $\rightarrow$ acceptable sentence structure with two minor errors

2 points $\rightarrow$ acceptable sentence structure with three minor errors

1 point $\rightarrow$ acceptable sentence structure with four minor errors

0 point $\rightarrow$ more than four errors or no answer was given

Participants were seniors of tourism majors at a vocational high school in new Taipei City. The researcher recruited participants through convenience sampling. The class who was taught by the researcher was assigned as the experimental group. They used the cloud language learning tool to practice English sentence patterns. The other class was assigned as the control group, and they did not use the cloud language learning tool. The two groups of students were then tested and compared for their performance. In this quasi-experimental study, both the two groups took a pre-test and a post-test. The entire research design is shown in Table 1.

Table 1. Research design

\begin{tabular}{llll}
\hline Group & Pre-test & Treatment & Post-test \\
\hline Experimental Group & $\mathrm{O} 1$ & $\mathrm{X}$ & $\mathrm{O} 2$ \\
Control Group & $\mathrm{O} 3$ & $\mathrm{C}$ & $\mathrm{O} 4$ \\
\hline
\end{tabular}

Note. O1、O3: English Writing Test; O2、O4: English Writing Test; X: Treatment—Cloud language learning tools; C: No treatment.

Ways of teaching was the independent variable in the present study. The experimental group, in addition to the handouts, was required to use the cloud language learning tool to practice sentence patterns, and the control group was not. English writing performance was the dependent variable. The mean score of the pre-test was then compared with that of the post-test. The controlled variables were the two groups were all senior vocational high school students, they were taught the same instructional material, and the research period were the same, one week.

Table 2. Teaching procedures for the experimental group and control group

\begin{tabular}{|c|c|c|c|}
\hline Procedure & $\begin{array}{l}\text { Traditional Teaching Method } \\
\text { (Control Group) }\end{array}$ & $\begin{array}{l}\text { Cloud Sentence Learning Environment } \\
\text { (Experimental Group) }\end{array}$ & \\
\hline $\begin{array}{l}\text { Presentation of } \\
\text { Sentence } \\
\text { Patterns: How } \\
\text { Teacher Presents } \\
\text { Sentence Patterns } \\
\text { to Students }\end{array}$ & $\begin{array}{l}\text { The teacher presents the } \\
\text { sentence patterns to be taught } \\
\text { on the board and explain these } \\
\text { patterns. } \\
\text { For example: } \\
\text { Exclamation } \\
\text { How + Adj. }+\mathrm{S}+\mathrm{Be} ! \\
\text { What }+(\mathrm{a} / \mathrm{an})+\text { Adj. }+\mathrm{N}+\mathrm{S}+ \\
\mathrm{V} !\end{array}$ & $\begin{array}{l}\text { Before class: } \\
\text { The teacher makes use of the cloud } \\
\text { sentence learning tool to create sentence } \\
\text { patterns to be taught: } \\
\text { 1. The teacher can choose from the } \\
\text { white columns and ask students to fill in } \\
\text { the blanks in the white columns and add } \\
\text { punctuations to create sentences as } \\
\text { shown on the right-hand side. }\end{array}$ & 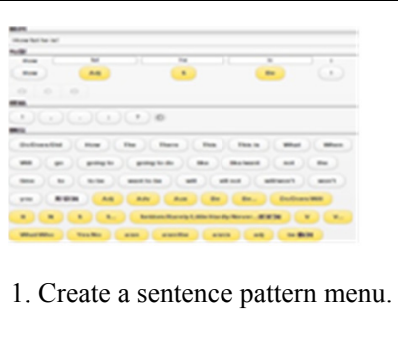 \\
\hline
\end{tabular}


2. The teacher can also add columns if needed as shown on the right-hand side. 3. The teacher can use the created sentence patterns to design classroom activities.

\section{During the class:}

The teacher can choose the sentence patterns to be taught from the sentence pattern menu as shown on the right-hand side.

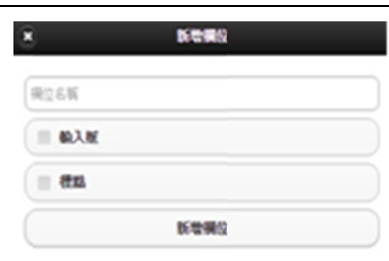

2. Dialogue box to add sentence patterns to the menu.

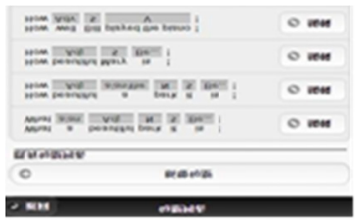

3. Design classroom activities to practice sentence patterns.

\section{Practice of} sentence patterns: Students practice on their own

\section{Practice sentence patterns:} Students use the paper handouts offered by the teacher to practice sentence patterns. 2. Examine students learning outcome: Ask students to write down the answers on the board to check if they have correct sentences.
Practice sentence patterns: Students may key in vocabulary words based on the order of the sentence patterns. For example:

1. Students may key in an adjective under the category Adj. as shown in Figure 1 on the right-hand side. Click the down arrow to key in vocabulary words as shown in Figure 2. Students are allowed to key in unlimited number of vocabulary words that they have learned. They can also repeatedly use the words they have chosen before. 2. After keying in the required vocabulary words, students can click the Create sentences button in the menu as shown in Figure 1 on the right-hand side to create a sentence. They can also revise or delete a sentence.

Examine students' learning outcome: The teacher may click the button of a student's name and check all the sentences he/she has created. Also, students' answers may be projected on the screen to be discussed with the entire class as shown in Figure 3 on the right-hand side.

3. Collaborative learning: Divided the entire class into seven groups. Each group is given a picture. Group members are encouraged to use their imagination to use the sentence patterns they have learned to create sentences. Each group is required to make at least four sentences. It is even better if these sentences are related in some way to one another. Students are required to make use of the cloud sentence pattern learning tool and then present the sentences in the class as a way of performance assessment.

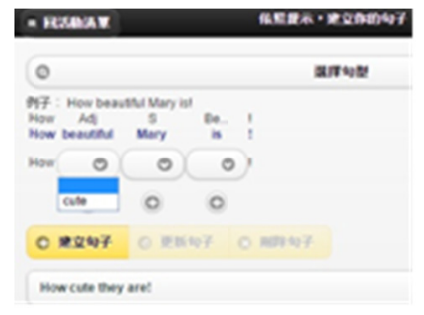

1.Columns for keying in vocabulary

\section{整加的显字}

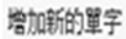

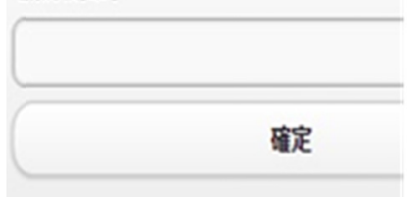

2.Students can add new vocabulary

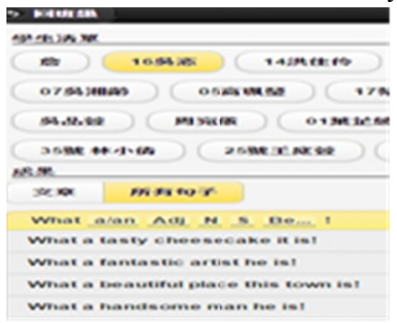

3.Check the sentences created by students
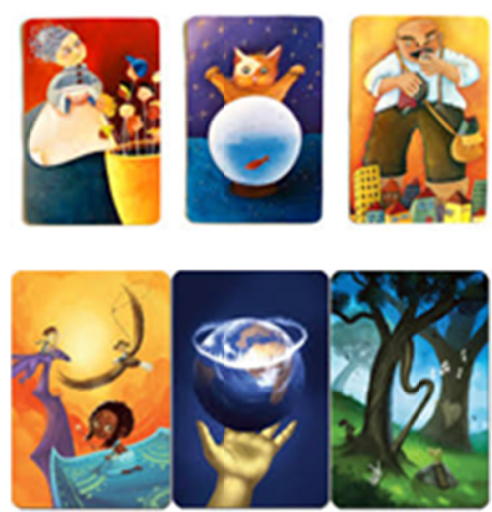

4. Hand out pictures for students to create their own sentences 


\begin{tabular}{|c|c|c|c|}
\hline \multirow{25}{*}{$\begin{array}{l}\text { Review } \\
\text { Activities: } \\
\text { Take-home } \\
\text { sentence pattern } \\
\text { exercises }\end{array}$} & \multirow{25}{*}{$\begin{array}{l}\text { Take-home practice: } \\
\text { 1. The teacher distributes } \\
\text { handouts concerning sentence } \\
\text { patterns and asks students to } \\
\text { practice sentence patterns at } \\
\text { home. } \\
\text { 2. Collect students' assignments } \\
\text { in next class meeting and check } \\
\text { their answers one by one. }\end{array}$} & \multirow{25}{*}{$\begin{array}{l}\text { 1. Practice at home: Students may enter } \\
\text { different sentence pattern practices as } \\
\text { shown in Figure } 1 \text { on the righthand side. } \\
\text { Based on what they have learned in the } \\
\text { class, students can create their own } \\
\text { sentences. } \\
\text { 2. The teacher does not have to wait } \\
\text { until he/she collects all the students' } \\
\text { answers to check accuracy of these } \\
\text { answers. The teacher may use the } \\
\text { "check" button to examine students' } \\
\text { learning of a particular sentence pattern } \\
\text { as shown in Figure } 2 \text { on the right-hand } \\
\text { side. The teacher can also get access to } \\
\text { each individual student's file to check } \\
\text { his/her learning history and to check the } \\
\text { accuracy of his/her answers as shown in } \\
\text { Figure } 3 \text { on the right-hand side. } \\
3 . \text { Extended learning: Ask students to } \\
\text { work in a group of three to look for their } \\
\text { own pictures and create their own } \\
\text { sentences based on what they have } \\
\text { learned. Each group is required to form } \\
\text { at least three sentences for two sentence } \\
\text { patterns. After completing the } \\
\text { assignment, each group is required to } \\
\text { upload the sentences, pictures, and voice } \\
\text { files to the Moodle platform. The } \\
\text { teacher can check students' performance } \\
\text { on Moodle and provide immediate } \\
\text { feedback. }\end{array}$} & \multirow{2}{*}{ Aancenthas - } \\
\hline & & & \\
\hline & & & 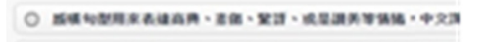 \\
\hline & & & 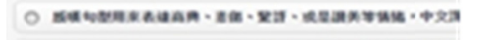 \\
\hline & & & 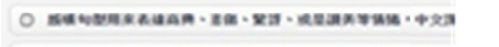 \\
\hline & & & 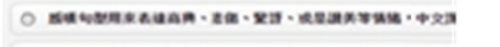 \\
\hline & & & 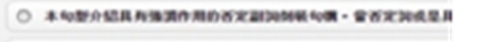 \\
\hline & & & 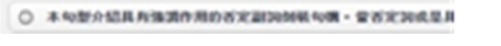 \\
\hline & & & $\begin{array}{l}\text { 1. Students can choose and practice sentence } \\
\text { structures }\end{array}$ \\
\hline & & & $\begin{array}{l}\text { rencon } \\
0 \quad \text { nexis }\end{array}$ \\
\hline & & & 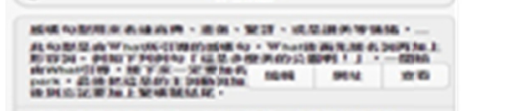 \\
\hline & & & 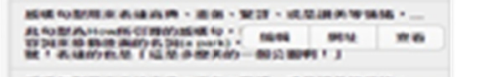 \\
\hline & & & 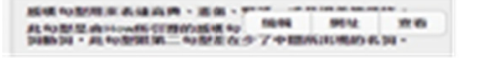 \\
\hline & & & $\begin{array}{l}\text { 2. Teachers can check students' writing } \\
\text { progress }\end{array}$ \\
\hline & & & \multirow{2}{*}{ 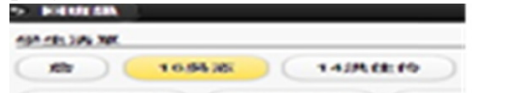 } \\
\hline & & & \\
\hline & & & 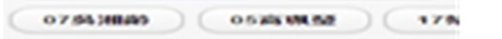 \\
\hline & & & 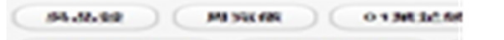 \\
\hline & & & 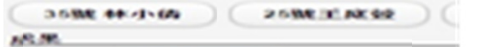 \\
\hline & & & 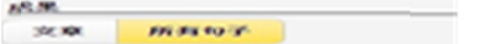 \\
\hline & & & \multirow{2}{*}{ 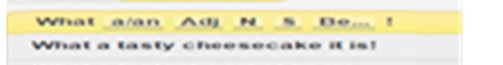 } \\
\hline & & & \\
\hline & & & whas a rantastie arkst ne is! \\
\hline & & & 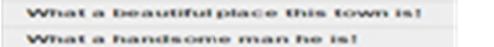 \\
\hline & & & $\begin{array}{l}\text { 3. Teachers can monitor students' learning } \\
\text { conditions. }\end{array}$ \\
\hline
\end{tabular}

\section{Data Analysis}

The present study applied one sample one-way ANOVA statistical method to analyze the data collected from students' English writing tests. The pre-test was treated as Covariate, and the post-test the Dependent Variable. The analysis is aimed to explore the differences, if any, between the experimental group and the control group in the dependent variable.

\subsection{Results}

The present study aims at exploring how the cloud language learning tool may improve vocational high school students' English writing skills. The experimental and the control groups of students took English Writing Ability Test before and after the instruction. The data collected were then analyzed, using one-way ANOVA statistical method. The pre-test scores are the Covariate and the post-test scores are the Dependent Variable. The results are as follows:

\subsection{Within Groups Homogeneity of Regression Coefficient}

Before doing ANOVA analysis, analysis of within groups homogeneity of regression coefficient had to be done in order to avoid interference between groups in the pre-test. Figure 4 shows that the $f$ value is $2.322(\mathrm{p}>.05)$, which was not significant. Thus, the researcher went ahead to do one-way ANOVA analysis to examine the difference, if any, between pre-test and post-test performed by the two groups. 
Table 3. Within groups homogeneity of regression coefficient (independent variable: post-test)

\begin{tabular}{llllll}
\hline Source & Type III sum of squares & df & Mean Square & F & Sig. \\
\hline Corrected Model & $16416.801 \mathrm{a}$ & 3 & 5472.267 & 32.794 & .000 \\
Intercept & 3007.190 & 1 & 3007.190 & 18.021 & .000 \\
Group & 848.585 & 1 & 848.585 & 5.085 & .028 \\
Total score of Pretest & 14854.160 & 1 & 14854.160 & 89.018 & .000 \\
Group * Pretest & 387.471 & 1 & 387.471 & 2.322 & .132 \\
Error & 10679.478 & 64 & 166.867 & & \\
Total & 203251.000 & 68 & & & \\
Corrected Total & 27096.279 & 67 & & & \\
\hline
\end{tabular}

Note. a. R Squared $=.606$ (Adjusted R Squared $=.587$ ).

\subsection{ANOVA Analysis of English Writing Ability}

Results of the one-way ANOVA analysis of the English writing ability of the experimental group and the control group as follows:

1) Table 4 shows that the mean score of the control group is 46.62 , and the mean score of the experimental group is 55.18 .

2) Table 5 shows that the group $F$ value is $4.563(p<.05)$, the different is significant. It is evident that the cloud language learning tool affects students' English writing skills. Table 4 also shows that the mean score of the experimental group is higher than that of the control. It also shows that the cloud language learning tool may improve students' English writing ability.

Table 4. Descriptive analysis of English writing proficiency tests

\begin{tabular}{llll}
\hline Group & $\mathrm{M}$ & $\mathrm{SD}$ & $\mathrm{n}$ \\
\hline Control group & 46.62 & 22.184 & 34 \\
Experimental group & 55.18 & 17.066 & 34 \\
Total & 50.90 & 20.110 & 68 \\
\hline
\end{tabular}

Table 5. ANOVA analysis of English writing test

\begin{tabular}{llllll}
\hline Source & Type III sum of squares & df & Mean Square & F & Sig. \\
\hline Corrected Model & $16029.330 \mathrm{a}$ & 2 & 8014.665 & 47.073 & .000 \\
Intercept & 2986.169 & 1 & 2986.169 & 17.539 & .000 \\
Total Score of Pre-test & 14784.021 & 1 & 14784.021 & 86.832 & .000 \\
Group & 776.936 & 1 & 776.936 & 4.563 & $.036^{*}$ \\
Error & 11066.949 & 65 & 170.261 & & \\
Total & 203251.000 & 68 & & & \\
Corrected Total & 27096.279 & 67 & & & \\
\hline
\end{tabular}

Note. a. R Squared $=.592$ (Adjusted R Squared $=.579$ ); $\mathrm{b} .{ }^{*} \mathrm{p}<0.05$.

\section{Conclusion}

Analysis of the data collected for the present study showed a significant f-value $4.563(\mathrm{p}<.05)$. It may reveal that the cloud language learning tool can affect students' English writing skills. That the mean score of the experimental group is higher than that of the control group further prove that the cloud language learning tool may help develop vocational high school students' English writing skills.

Based on the teacher's observation, it takes time for students to learn to make use of the cloud language learning tool to create short essays. Therefore, the researcher developed a three-stage curricular activity. In the first stage, the teacher provides vocabulary words and sentence patterns, and students make use of the cloud language learning tool to form different sentences. Then, after being familiar with the cloud language learning tool, students may provide their own vocabulary words and use the sentence patterns available in the tool to create a short essay. In the third stage, students are encouraged to create their own sentence patterns and provide their own vocabulary words to produce short essays. This three-stage cloud language learning curriculum may also be combined with computer animation and applied to elementary school students to motivate students to learn. Hopefully, this cloud language learning program may prevail in schools of different levels. 


\section{Acknowledgements}

The author would like to thank Chih-Hong Chiang, You-Syun Ling \& Ling-Hsuan Chu for their devotion to the research study.

\section{References}

Bukhari, S. S. F. (2016). Mind Mapping Technique to Enhance EFL Writing Skill. International Journal of Linguistics and Communication, 4(1), 58-77. https://doi.org/10.15640/ijlc.v4n1a7

Buran, A., \& Filyukov, A. (2015). Mind mapping technique in language learning. Procedia - Social and Behavioral Sciences, 206, 215-218. https://doi.org/10.1016/j.sbspro.2015.10.010

Chen, C-F., \& Chu, L-H. (2015). A Study of "cloud platform as a teaching supplementary aid" in promoting vocational high school students' English writing abilities. Paper presented at the 2015 Taiwan Association for Educational Communications and Technology conference, National Taiwan University, Taipei, Taiwan.

Chen, L. A. (2006). Theory and Practice of Teaching Creative Thinking (6th ed.). Taipei: Psychology Co.

Chiang, C-H. (2014). A study of "digital storytelling” through mandala thinking method in promoting seven graders' English writing abilities. Unpublished master's thesis. Tamkang University, New Taipei City, Taiwan

Imaizumi, C. (1989). Mandala Notebook. Taipei: Coolbooks.

Kellogg, R. T. (1988). Attentional overload and writing performance: Effects of rough draft and outline strategies. Journal of Experimental Psychology: Learning, Memory, and Cognition, 14(2), 355-365. https://doi.org/10.1037//0278-7393.14.2.355

Kellogg, R. T. (1996). A model of working memory in writing.

Levy, B. A., Newell, S., Snyder, J., \& Timmins, K. (1986). Processing changes across reading encounters. Journal of Experimental Psychology: Learning, Memory, and Cognition, 12(4), 467-478. https://doi.org/10.1037//0278-7393.12.4.467

Levy, C., \& Ransdell, S. E. (1996). The science of writing: Theories, methods, individual differences, and applications. Lawrence Erlbaum Associates, Inc.

Lin, Y-S. (2014). A research on the development of a cloud platform as a supplementary aid to teaching English sentence patterns. Unpublished master's thesis. Tamkang University, New Taipei City, Taiwan.

Saddler, B. (2005). Sentence combining: A sentence-level writing intervention. Reading Teacher, 58(5), 468471. https://doi.org/10.1598/RT.58.5.6

Saddler, B., \& Asaro, K. (2008). Beyond noun-verb: The use of sentence combining to improve sentence writing ability. Insights on Learning Disabilities, 5(2), 41-50.

Saddler, B., Behforooz, B., \& Asaro, K. (2008). The effects of sentence-combining instruction on the writing of fourth-grade students with writing difficulties. Journal of Special Education, 42(2), 79-90. https://doi.org/10.1177/0022466907310371

Vijayavalsalan, B. (2016). Mind mapping as a strategy for enhancing essay writing skills. The New Educational Review, 3(44), 137-150. https://doi.org/10.15804/tner.2016.45.3.11

\section{Copyrights}

Copyright for this article is retained by the author, with first publication rights granted to the journal.

This is an open-access article distributed under the terms and conditions of the Creative Commons Attribution license (http://creativecommons.org/licenses/by/4.0/). 